\title{
Competing biosecurity and risk rationalities in the Chittagong poultry commodity chain, Bangladesh
}

\author{
Erling Hog' (D) Guillaume Fournié ${ }^{2}$ • \\ Md. Ahasanul Hoque ${ }^{3} \cdot$ Rashed Mahmud $^{3}$. \\ Dirk U. Pfeiffer ${ }^{2,4}$. Tony Barnett ${ }^{1}$
}

\begin{abstract}
This paper anthropologically explores how key actors in the Chittagong live bird trading network perceive biosecurity and risk in relation to avian influenza between production sites, market maker scenes and outlets. They pay attention to the past and the present, rather than the future, downplaying the need for strict risk management, as outbreaks have not been reported frequently for a number of years. This is analysed as 'temporalities of risk perception regarding biosecurity', through Black Swan theory, the idea that unexpected events with major effects are often inappropriately rationalized (Taleb in The Black Swan. The impact of the highly
\end{abstract}

\author{
Erling Høg \\ Erling.Hoeg@1shtm.ac.uk \\ Guillaume Fournié \\ gfournie@rvc.ac.uk \\ Md. Ahasanul Hoque \\ md.hoque@my.jcu.edu.au \\ Rashed Mahmud \\ rashed.mahmud1@gmail.com \\ Dirk U. Pfeiffer \\ dirk.pfeiffer@cityu.edu.hk; pfeiffer@rvc.ac.uk \\ Tony Barnett \\ Tony.Barnett@1shtm.ac.uk
}

1 Department of Global Health and Development, London School of Hygiene \& Tropical Medicine, 15-17 Tavistock Place, London WC1H 9SH, UK

2 Department of Pathobiology and Population Sciences, Royal Veterinary College, Hawkshead Lane, Hatfield, Hertfordshire AL97TA, UK

3 Faculty of Veterinary Medicine, Chittagong Veterinary and Animal Sciences University, Zakir Hossain Road, Khulshi, Chittagong-4225, Bangladesh

4 Department of Infectious Diseases and Public Health, College of Veterinary Medicine and Life Sciences, City University of Hong Kong, 31 To Yuen Street, Kowloon Tong, Hong Kong 
improbable, Random House, New York, 2007). This incorporates a sociocultural perspective on risk, emphasizing the contexts in which risk is understood, lived, embodied and experienced. Their risk calculation is explained in terms of social consent, practical intelligibility and convergence of constraints and motivation. The pragmatic and practical orientation towards risk stands in contrast to how risk is calculated in the avian influenza preparedness paradigm. It is argued that disease risk on the ground has become a normalized part of everyday business, as implied in Black Swan theory. Risk which is calculated retrospectively is unlikely to encourage investment in biosecurity and, thereby, points to the danger of unpredictable outlier events.

Keywords Bangladesh - Commodity chain - Avian influenza - Risk perception · Biosecurity · Ethnography · Epidemiology

\section{Introduction}

The highly pathogenic influenza virus H5N1 is endemic in Bangladesh (Ahmed et al. 2012b; Osmani et al. 2014). 555 avian influenza outbreaks were reported in 51 of the 64 Bangladeshi districts over the 10-year period 2007-2017 (OIE 2018). ${ }^{1}$ Chittagong experienced 32 outbreaks during 2008-2011 of which 75\% occurred in 2008 and 2009. ${ }^{2}$ No new outbreaks have been reported in Chittagong since March 2011. Consequently, the actors in the Chittagong live poultry sector ${ }^{3}$ perceive the likelihood of new outbreaks to be very low. Indeed, outbreaks may have happened, but have not been reported, due to the lack of compensation, poor disease surveillance systems, farmers' non-cooperation and the difficulty of differential diagnosis from Newcastle disease. Yet, their low risk perception may be influenced by the fact that the epidemiological authorities do not inform them about new outbreaks. They would only know, if the outbreaks received intensive media coverage, as they did during the peak years. Individually and collectively, they do not perceive, recognize and take preventive action against the potential danger of avian influenza, according to rigorous disease control recommendations. This is not

\footnotetext{
${ }^{1}$ Highly Pathogenic Avian Influenza, H5N1, was first reported in Bangladesh among backyard chickens in the northern Jamalpur district in January 2007. The virus had spread to 47 of the 64 districts by April 2008 (Brooks et al. 2009). By March 2013, Bangladesh had reported 549 H5N1 outbreaks in 51 districts (431,981 infected birds, 2,282,756 susceptible birds) (OIE 2013).

2 There have been three major waves of H5N1 outbreaks in the southern Chittagong district: JanuaryApril 2008 (17 outbreaks), January-September 2009 (7 outbreaks) and February-March 2011 (7 outbreaks). There was only 1 reported outbreak in 2010. In total, Chittagong experienced 83,680 reported cases of H5N1 in birds between 2008 and 2011. Additionally, 83,036 susceptible birds were destroyed. This gives a total of 113,716 dead birds attributed to avian influenza in three years (OIE 2013).

3 Poultry production in Bangladesh falls into three broad categories: (1) industrial and integrated; (2) commercial (large and small scale); and backyard (1-60 birds). Chicken and duck production has grown from 23 million in 1961 to 313 million in 2015 (FAOSTAT 2015; MoP 2015, p. 277). About five million people are employed in large-scale and small-scale poultry farms (Nasreen et al. 2013). Here we focus on common broiler chickens, crossbred Sonali chickens and egg laying hens, situated in the commercial sector between independent farmers and live bird markets.
} 
unique to Bangladesh. The actors argue that there have been no dangers for a number of years and, therefore, do not need strict risk management.

Actors in the commodity chain, between domestic production sites, market maker scenes and outlets, measure risk retrospectively, not prospectively. Like in Nassim Taleb's Black Swan theory, the idea that unexpected events with major effects are often inappropriately rationalized (Taleb 2007), observers accumulate wisdom after an event has happened. They assess risk looking to the past, weighed against their current resources. Such hindsight bias may influence the way the actors calculate risk, which stands in contrast to how risk is calculated in the foresight preparedness paradigm underlying current disease control strategies. However, it does not mean that actors in hindsight will say: 'if we had made biosecurity improvements we could have prevented poultry diseases and mortality.' On the contrary, they tend to downplay the need for strict risk management, as outbreaks have not been reported for several years. In other words, their hindsight bias is way of justifying their current minimal attention to preventive biosecurity practices. We term this phenomenon temporalities of risk perception regarding biosecurity. Such hindsight bias must be seen in a context of limited resources and limited knowledge about avian influenza. The actors pay more attention to immediate everyday businessrelated risks than to disease-associated risks. Nevertheless, they have developed strategies to mitigate economic losses which may increase the risk of infection for birds and humans alike. Such strategies lower adverse effects on livelihood, even when the probability of infection may, in scientific terms, be high. Such time-related calculated risk-what has happened in the past, what can practically be done in the present and what may happen in the future-points to the danger of unpredictable Black Swan outlier events (Taleb 2007).

It is a way of rationalizing past events, however inappropriately, as if avian flu could be explained and coped with in hindsight. Taleb defines a Black Swan event by its rarity, extreme impact and retrospective (though not prospective) predictability. The highly expected scenario that an event will not happen is also a Black Swan (ibid.). In other words, a Black Swan is an unpredictable outlier event and humans have a miserable track record in predicting such events. Taleb communicates by way of analogy how human beings think they can understand events in retrospect: "we are drivers looking through the rear view mirror while convinced we are looking ahead" (Taleb 2004).

Towards understanding such hindsight bias, how it is embedded in a multitude of circumstantial factors like poverty, ignorance, disbelief, aspiration, inability and reluctance among the actors in relation to the protection against avian influenza, we adopt a sociocultural perspective on risk, emphasizing the social and cultural context in which risk is understood, lived, embodied and experienced (Lupton 2013, p. 36). We apply a classical functional structuralist approach, assessing how different groups of actors perceive risk and biosecurity and how they follow or deviate from accepted preventive behaviour. This exposes different risk perceptions and biosecurity practices among the actor groups along the food chain. We are interested in how their situated meanings and understandings of risk influence their risk approaches. The macro-context of Bangladesh stipulates an unregulated poultry sector in which action against avian influenza is left largely to the agents in the 
poultry commodity chain. ${ }^{4}$ It is for this reason that we focus on the micro-contexts of everyday life.

We compare hatchery, farm, feed dealer, middleman and market biosecurity in the Chittagong ${ }^{5}$ live bird trading network, capturing the practices that facilitate the movement of pathogens. It draws on insights from multispecies ethnography (Haraway 2008; Kirksey and Helmreich 2010; Kirksey et al. 2014; Ogden et al. 2013; Porter 2013) and studies of material culture (Appadurai 1986b).

\section{Birds and people}

Such comparison requires analytical engagement with questions of structure and agency and ethnographically with commodities on the move, human bird handling practices, relationships and interactions. Birds and people have become joint subjects in disease regulation, subject to similar biological risks (Porter 2012b, p. 35), but within a chain of different practices and different risk perceptions. Conducting ethnographic fieldwork among people working in a poultry commodity chain between hatcheries and live bird markets raises the question of how to situate and contextualize the ethnographic subject matter (Marcus 2002). Trade in poultry involves people who take care of business matters and people who transport the birds between the transaction sites. Mobility, a multiplicity of sites, flows and circulations of bird commodities characterize the trading network. This represents a challenge for defining the appropriate scale, representativeness and appropriate methods of data collection.

We conducted individual interviews, locating informants through gatekeepers and snowball sampling (Hammersley and Atkinson 2007). This produced 173 interviews with 144 informants at 33 sites. We interviewed backyard farmers, independent farm managers and workers at small-, medium- and large-scale farms, middlemen and their employees, feed dealers, field veterinarians, live bird market vendors, hatchery managers and workers and government livestock officers. Focus groups were organized with feed dealers, middlemen and field veterinarians. Grand and mini tour observations (Spradley 1980) were produced at 4 backyard farms, 10 commercial farms, 2 hatcheries and 2 poultry unloading sites.

Multi-site fieldwork, applying a range of research strategies, presents practical, methodological and analytical challenges. Multi-site fieldwork provides an

\footnotetext{
4 The Bangladeshi government made two national plans (in 2006 and 2009) to manage avian influenza. It recognized its shortcomings in terms of both preparedness and response. Routine active surveillance is not currently implemented, because of human resource constraints for surveillance, prevention, health education and laboratory diagnosis. Health facilities and equipment remain inadequate (MoFL 2006, p. 21). Instead, the Department of Livestock Services depends on a passive surveillance system (MoFL 2009 , p. 17), awaiting poultry mortality reports from the farmers. Not all farmers report mortality, fearing financial loss from compulsory culling (Gregory et al. 2010).

5 Bangladesh is a lower middle-income country with a rapidly growing population on a surface area of $148,460 \mathrm{~km}^{2}$. One of the most densely populated countries in the world at 1,222 people per $\mathrm{km}^{2}$, its population increased from 48 million in 1960 to 159 million in 2014 (World Bank 2015). Chittagong administrative division in the southeast, geographically the largest covering a quarter of the country, contains a fifth of this population.
} 
understanding of connections and relationships, enabling researchers to move from site to site producing, juxtaposing and triangulating field data. It requires researcher physical and intellectual mobility, recognizing that 'site' means 'location', 'place' and 'time' but also socially produced space and analytical 'perspective', which points to methodological and epistemological convergence (Falzon 2009). Inductive ethnography follows a cumulative path: you discover the field and start thinking in new ways about how and what to ask, taking into consideration previous unknown ideas and relations (Marcus 2007, p. 1132), uncovering new ethnographic questions which generate juxtapositions and comparisons (Marcus 1995, p. 102). The ethnographic chronicle of risk and biosecurity begins in a hatchery and will continue among feed dealers, middlemen, poultry transporters and farmers.

\section{Competing risk rationalities}

\section{Hatchery managers}

Anamika, a hatchery manager, explained zoonotic disease prevention: ${ }^{6}$

Normally we use masks, gloves and aprons to protect ourselves against the risk of exposure to avian influenza and other viruses. We maintain strict biosecurity to protect against avian influenza. We spray the body and take a footbath before entering the hatchery.

This hatchery brings eggs from its own breeder farm in its own company vehicles. It also transports the day-old chicks in its own vehicles to feed dealers and large-scale commercial farms. Twice a week, the hatchery sends day-old chicks directly to farmers or indirectly via feed dealers. Anamika explains what they do to avoid disease spread between premises:

We grade the chicks up to level. We cull all substandard chicks. Then we vaccinate the healthy and standard chicks. ${ }^{7}$ We pack them in chick boxes. Then we load the vehicle with chick boxes and transport them to the dealers and sometimes to the farms directly.

This exemplifies the commodity phase and evaluation of commodity candidacy, as part of a tripartite commodity situation: phase, candidacy and context (Appadurai 1986b). They grade the birds qualifying as commodities and kill the birds that disqualify. This process is governed in regular ways, biosecurity complementing business.

\footnotetext{
${ }^{6}$ Eight humans (children and poultry workers) have been reported infected with H5N1 or H9N2 in Bangladesh, since 2008. They were exposed to live, sick or dead poultry during slaughter or meat preparation (WHO 2008, 2011a, b, 2013, 2015, 2016; ICDDRB 2011, 2013; IEDCR 2012a, b; Brooks et al. 2009).

7 Marek's disease vaccine is given to layer chicks. If required by the feed dealer or farmer, then the layer chicks are also given avian influenza vaccine at the hatchery. Broiler chicks are not vaccinated at the hatchery.
} 
There are about 120 hatcheries across the country, half of them located in Gazipur, Dhaka and Chittagong districts. But only 50 hatcheries are fully functional of which 11 are government owned (Begum et al. 2011, p. 11). Another hatchery manager explained that the biggest problem remains electricity failure and mechanical breakdowns.

Hatchery biosecurity is strictly maintained, because the stakes are high and the hatchery stands at the origin of the commodity chain. Establishing a hatchery necessitates large investment capital and disease outbreaks will have dramatic adverse economic consequences. Thus, investment in biosecurity is incorporated as a necessary budget allocation. Investment in biosecurity remains essential and it can be maintained, because of their apex position: hatcheries have predictable income and profit, unlike most farmers.

\section{Feed dealers}

Feed dealers receive chicks from the hatcheries, reselling them to farmers. When asked about common risks in their daily work, they did indeed mention disease risks, but they were more concerned about recurrent and predictable risks in their everyday business: accidental risks, their likely inability to sell all their live consumables on a given day, fluctuating poultry prices and, not least, problems with money recovery from middlemen and farmers. Indeed, disease risk and other business risks may seem inseparable: a disease outbreak leads to economic loss or less profit than expected. Morbidity and mortality in a poultry flock leads to disqualification of birds as commodities. Both demand and price may decrease as a consequence of these factors. Yet, as Eyad explained, in the presence of 12 other feed dealers: "Yes, I see business risk in terms of problems with money recovery, but in terms of disease risk, then I see no risk". Bari added a Black swan perspective: "I don't do anything to protect against the exposure to avian influenza, as there is no history of avian flu in my area. I don't receive any birds with avian flu, so there is no chance of getting it". This could be explained by the fact that feed dealers do not store birds. Therefore, there are no real risks that feed dealers will experience sick and dying birds between their purchase from farmers and their sales to middlemen or markets. This implies that feed dealers do not run a business risk when birds sicken and die and that disease outbreaks merely affect the farmers and to a smaller extent the middlemen who organize the transportation of birds between farms and markets. Feed dealers, farmers and middlemen do not share profit and loss. They do not share risk because they do not share the same transaction time period. In other words, risk is time dependent. The shorter the period you hold the birds, the better for your business as the risk is low. For feed dealers, it is even better not to hold birds at all but rather to deal in fungible money. In business, it is usually best to aim for maximum fungibility at all times.

Feed dealers agreed that poultry diseases are common in Bangladesh. They were concerned about poultry diseases, varying quality of drugs and vaccines, risks for the poultry sector, when selling sick birds, and bird mortality during transportation. They mentioned ranikhet (Newcastle disease) and gumboro (infectious bursal disease), but not avian influenza. Seeing no risk in their daily work was explained as 
a matter of adaptation to everyday work practices. They trust the current hygiene practices. In business terms, this may be explained by the fact that they can afford to do so from their position in the poultry commodity chain structure: they have little reason to be concerned about system-related risk. Other than that, they associated risk with accidents while riding a motorbike, electric shock from poorly maintained equipment and feed sacks that could fall down on birds and chicks.

During the final focus group interview, the feed dealers were invited to raise issues as a professional group. First, they want to know how to protect themselves and their employees against avian influenza. They agreed that they are doing well in most aspects of their occupation, except avian influenza. Second, they raised questions about three business risks, none of them being specific disease risks. These may appear contradictory to the issues raised during individual interviews, but they may reflect a group consensus:

1. Price increase: Hatcheries may increase the price of day-old chickens. This happens before the religious festivals, e.g. Eid, Durga Puja, Mohorom and Bangla New Year. Vaccination and spray of chicks may also lead to price increase.

2. Business competition: The large industrial poultry companies may influence the poultry sector in ways that threaten the feed dealer business, operating in the live bird sector of independent poultry farmers. The feed dealers fear their business may disappear in the future.

3. Price drop below market price: The price of poultry may drop below the market price due to events in the poultry commodity chain.

Individually and collectively, feed dealers do not prioritize the prevention of an unpredictable disease like avian influenza that they have not seen happening for a number of years. This also becomes evident among their closest business relations, the middlemen.

\section{Middlemen}

Middlemen organize the transportation of birds between farms and markets, while their employees do the actual bird transfer in vehicles. Dider, a middleman based at a live bird market in Chittagong City, buys broilers directly from 50 feed dealers and 5-6 brokers. On average, Dider sells 2500 broilers per day to 30 Chittagong City live bird markets. He employs 20 workers, who handle birds every day. They do not wear personal protective equipment to protect against zoonotic transmission. Dider explains this as a matter of tacit agreement among poultry traders. There would be no reason to protect against avian flu during a disease-free Black Swan period.

I realize that there might be health risks for my employees, but I let them do their work. The common perception is: if employees use personal protective equipment, then the customers would become suspicious. Why are they wearing PPE? Are the birds sick? But if everyone were wearing PPE, then it 
would a different scenario. Then customers would perceive the use of PPE differently.

The middlemen were not concerned about avian influenza, but, as in the case of feed dealers, worried about everyday risks: feed and storage costs when the birds are in their possession, traffic jams, indirect cash transactions, bird handling risks, police harassment and hijacking. Before the birds are sold at the markets, the middlemen must maintain quality commodities. This means they have to pay to feed and store the birds while in transit. Many middlemen have overnight storage rooms for unsold surplus of birds at the end of the day.

Nazir: During the transportation of birds, they may get sick or die because of long distance travel. If I don't sell all my birds to the markets in one day, then I will have to keep them overnight in my storage room. This sometimes causes reduced body weight, which then creates an increase in feed costs. Some of the birds die, due to these problems during overnight storage.

Transportation takes longer in the frequent traffic jams in Bangladesh, meaning that many birds may die, particularly during the summer heat. Bird mortality and weight loss lead to economic loss. The problem of indirect cash transactions refers to their worry about dishonesty among their employees. Additionally, they mentioned police harassment. The police frequently stop poultry vehicles and ask for bribes. In rare cases, thieves attempt to hijack poultry vehicles.

Nazir: In rare cases, I experience attempts to kidnap my vehicle full of birds.

But I experience a more common problem: Police men frequently stop the vehicle, when we transport birds and they commonly ask for bribes.

The police check, whether the drivers carry poultry health certificates issued by the livestock authorities, necessary by law. They ask for bribes, in case the poultry transporters do not have such documentation.

In terms of disease risk, the middlemen were mostly concerned about physical harm and accidents, for example, when birds get sick and die during transportation or local storage. They also worry that hatcheries sometimes deliver second- or thirdquality chicks. Generally, middlemen do not have direct contact with birds. Therefore, they do not see any risk for their personal health in their daily work. Even some of those who do have direct contact with birds see no risk for humans, as they have never knowingly experienced illness due to bird contact. Yet, as Dider explained earlier, bird handling risk is part of their everyday work-a calculated risk, based on their experience and consequently on what they see as the most convenient and appropriate everyday practice. Such calculated risk-what has happened in the past, what can practically be done in the present and what may happen in the future-points again to the danger of unpredictable outlier events (Taleb 2007). 


\section{Middlemen employees}

Such time-dependent, experientially shaped risk perception also predominates among their employees, every day handling live birds bare handed. That is, middlemen employees act as the key bird movers. Upon receiving orders from feed dealers and middlemen, they visit poultry farms to pick up birds and then deliver them to live bird markets. Rahim has worked as a middleman employee for 16 years, continuing the pattern of working late at night every other day, after a long night's work traveling $6 \mathrm{~h}$ between Chittagong and his hometown and sleeping during the day. His colleagues work on his days off. He works with his bare hands: "If I wear gloves, then I am not feeling comfortable at all. And I cannot load and unload the truck quickly. During the summer, it creates rashes and blisters as well, when I am wearing gloves".

Rahim may wear a mask and gloves during the winter, when the risk of getting ill is highest, and he always makes sure to take a shower, when he comes home from work. Eventually wearing a mask and gloves gives him protection against getting ill in general. This is not a conscious choice to protect against avian influenza in particular. In fact, Rahim admits his ignorance about avian influenza: "I have no idea about it". He reflects on the question, whether the risk of human exposure to avian influenza would be minimized, if one or more of his daily practices were changed: "Nothing changes in our daily work to minimize the risk of avian influenza, because nowadays we all know there is no avian flu in Bangladesh". Is this an example of false confidence by relying on hindsight bias? As explained earlier, the Black Swan is an unpredictable outlier event.

In retrospect, he recalls the avian influenza outbreaks among birds during 20082011. Farmers wanted to sell all their birds quickly, maintaining their commodity candidacy by reducing the price. They feared their birds would turn into noncommodities, which would affect their business negatively.

Rahim: At that time, many birds died due to this disease. We bought more poultry at a cheaper rate, because farmers wanted to sell their birds quickly. Sometimes we bought healthy birds from the farms, but during the transportation many birds died on the truck. Suddenly my owner lost a lot of money. Customers lost interest in buying poultry and the market price suddenly dropped. But I think we have recovered by now.

Rahim's final statement "but I think we have recovered by now" is another example of hindsight bias. Most informants reflect in this way: they underestimate the need to protect against avian influenza during times with no outbreaks. Did you know that avian influenza viruses can transmit from birds to humans? Rahim laconically replies: "No".

Like feed dealers and middlemen, the poultry transporters were not concerned about the risk of avian influenza, but worried about the risks they face in their everyday working life: police harassment, hijacking and road accidents. They see these problems as the main risks. Secondarily, they mention that feathers and dust may cause allergy, colds, coughing and fever. But they are not sure whether working with poultry represents a particularly important cause of ill health, 
reasoning that all people eventually suffer such common illnesses. They always work with their bare hands and have found ways to avoid getting bitten by the birds.

The middlemen employees experienced the impact of avian flu during the 20072012 outbreaks. This is an example of an epidemic on the move as a social disease, in that human practices along the commodity chain determined the course of the epidemic. Actors predominantly engaged in reactive behaviours, not preventive ones. Farmers wanted to sell their poultry quickly at a cheaper rate to avoid the consequences of having sick birds on their farms. The middlemen bought apparently healthy birds, but many birds died during transportation. That middlemen buy from several farms means that sick birds get mixed with healthy birds. But why do farmers refrain from engaging in preventive behaviours, mostly turning to reactive behaviours in case of a disease outbreak?

\section{Farmers}

Farmers explain that they do not invest in biosecurity, because of economic predicaments, collective behaviour and the limits of conceptual biosecurity. Some farmers 'do not see any risk'. This can be explained in two ways. The first variation 'you know about risk, but do not see any risk' relates to the phenomena emphasized in Black Swan theory: risk perception is based on what the farmers have experienced in the past, not so much what may happen in the future. They had not experienced or heard about avian influenza for more than 5 years. The second variation 'you have no clear idea what risk means and therefore do not see any risk' appears to mean: 'you cannot perceive risk, if you have no idea what it is'. In addition, some farmers could not provide an explanation as to why they do not invest in biosecurity to prevent future disease outbreak. This remains a black box phenomenon. We do not know more than the fact that farmers simply cannot explain why they do not invest in preventive practices to avoid poultry disease outbreaks. These farmers may not know what risk is and/or what biosecurity is. Moreover, most farm managers do not own the farms, so they explained that they have no authority to invest in biosecurity. This might be a case of evasive prevarication, escaping the responsibility for not investing in biosecurity, but it could also be a case of unaccountability among the, otherwise absent, farm owners. Additionally, some farmers explained that they spend much of their time doing other businesses, because poultry farming has turned out to be economically unprofitable. This applies to rich and poor farmers alike and to any farm size. A farmer may spend more time at a downtown clothes shop, or as a middleman or feed dealer than on his farm.

In terms of conceptual biosecurity, the farmers referred to the presence of trees and the large number of crows at their farms, indicating a fear that the crows would transmit disease to animals and humans. In comparison, Vietnamese poultry farmers explained non-human environmental factors as circumstances exempting them from responsibility for disease control (Porter 2012a, p. 104). Some farms were built before the development of surrounding residential areas and this hampers improvement of conceptual biosecurity. 
Habib, Mahmudul and Hafizur, small-, medium- and large-scale farmers, respectively, have implemented little to no bioexclusion and biocontainment measures. Their farms are in residential areas. Crows are sitting in the trees. The farmers and their workers are not wearing gloves, masks, aprons or protective shoes. Local chickens and ducks wander freely around the farm premises. They keep feed bags, litter and solid waste inside the poultry sheds. Habib and Mahmudul explain that they are too poor to invest in biosecurity.

Habib: Since I am poor, I face the problem of money to improve biosecurity. Other than that, I have no problem. I plan to rebuild my existing poultry house, which is now made of steel, turning it into a four-story building. I also plan to make my farm larger and make a boundary of concrete, instead of the one I have made by steel plates. But it all depends on my financial situation.

Chicken farming does not provide sufficient income to support Habib and his dependents, so he runs a clothes shop in the town centre. This also affects his farm management, because of his absence.

Habib: I have the clothes shop in the town centre and this is my primary business. Every day in the morning after finishing my work at my poultry farm, I go to the shop and in the evening, I come back. So, when I am away, then my father-in-law looks after my poultry farm. I am poor and sometimes there are no chickens at my farm, so I have to do both businesses.

Mahmudul explains the constraints of conceptual biosecurity and economic predicaments.

Mahmudul: You know that my farmhouse is located within a residential area. So, I cannot do much to improve biosecurity. The fact that I am poor is also one of the major challenges. The biggest challenge is that the poultry price is not fixed. It always varies, while the feed price is always stable and high. So, I cannot predict how much I gain from one batch of Sonali. So, my income is not fixed. This is why I cannot make a plan to improve biosecurity. You know, everything in the world depends on money.

Mahmudul has improved his farm biosecurity, both bioexclusion and biocontainment.

Mahmudul: In the beginning, I hadn't even heard the word biosecurity. At that time, anyone could enter my farmhouse. Now I have made some changes. I no longer give the middleman employee permission to enter my farmhouse. In the beginning, I did not bury the dead birds, but now I bury all dead birds deep in the ground, 3 feet down.

Hafizur is concerned about controlling fatal diseases at the farm. Yet, overall biosecurity is unsatisfactory. Hafizur rents this farm and he therefore has no authority to change biosecurity practices. Moreover, although he is managing a large-scale farm, this is not his primary job. He cannot make a living from poultry farming and he is mostly absent from this large-scale poultry farm, spending most of 
the daily business hours as a poultry middleman. He sees this as a major challenge for attending to biosecurity issues. Hafizur explains:

Hafizur: You already know that this is not my farm, I just rent it from the farm owner and my farm house is located in a residential area. So, I cannot improve biosecurity. Also, I have another business: this is one of the major challenges.

In terms of contact zones, hotspots, flows and mobilities, Habib does business with 1 feed dealer, 6 middlemen, 8 retailers and 3 wholesalers, Mahmudul with 1 feed dealer and 1 middleman and Hafizur with 3 feed dealers, several farms, 12 wholesalers and 18 retailers. Birds are mixed as a generic commodity between the actors in the commodity chain. Feed dealers, middlemen, market retailers and wholesalers buy chickens from several producers, changing source farms from one purchase cycle to another.

How does this make sense in terms of disease surveillance, control and epidemiology? Do poultry farmers with many business relations complicate the risk of disease transmission? They may unwittingly trade in viruses. Think of the situation in which Habib sells 500 broilers with asymptomatic infection. No one can tell. The chickens appear healthy. The chicken transporter adds the 500 birds onto his truck, mixed with 3,000 other broilers from other farms. The 3,500 birds are then unloaded in Chittagong and sold to different market vendors in batches of between 20 and several hundreds. The 500 sick chickens from Habib's farm may now infect thousands of other chickens in several retailer shops at different live bird markets. Moreover, it will be impossible to trace the disease to Habib's farm and sick birds will be sold to consumers at several live bird markets.

Infected chickens have a latency period, an asymptomatic infectious period and a symptomatic infectious period. Infection with highly pathogenic influenza A virus (H5N1) would generally result in the rapid death of infected chickens within 23 days. Symptom onset would be preceded by a period of asymptomatic viral shedding lasting about $24 \mathrm{~h}$ (Bouma et al. 2009). In contrast, ducks may not die of the infection or show any symptoms (Hulse-Post et al. 2005). In fact, the chickens can be picked up and delivered to the live bird markets and passed on to the consumers, slaughtered or alive, within the latent non-infectious and asymptomatic infectious periods.

We found four explanations in economic terms as to why farmers do not invest in farm biosecurity: income volatility, poverty, credit reliance and cost of intervention. First, poor farmers observe the dynamics of the poultry business and act accordingly to maximize profit and minimize losses, since they cannot predict their income. We argue that this is rational behaviour. One of the primary outcomes of such income volatility is to sacrifice investment in farm biosecurity. Second, poor farmers explain that it all depends on the 'money in my pocket'. The sale price of poultry always fluctuates, while the price of feed remains high and stable. Farmers cannot predict their income and they are too poor to improve biosecurity.

We think this relates to rational self-interest decision-making. Investing in biosecurity depends on belief in predictable income and profit. Given their circumstances these farmers are unable to secure capital to invest in biosecurity. Third, we could assume that credit reliance limits the investment in biosecurity, but 
cash farmers do not invest in biosecurity more than credit farmers. Fourth, many farmers 'have a biosecurity plan for the future', but cannot predict the day when they will have sufficient capital to implement such a plan.

A farmer investing heavily in biosecurity would be viewed with suspicion: 'his birds must be sick'. They fear ridicule and stigmatization. Thus, contrary to what we might expect, investment in biosecurity could adversely affect a farmer's reputation. Anthropological studies support our findings among farmers: poor biosecurity, low risk perception, financial inability, but also emphasize the still vaguely understood phenomenon of 'inconvenience' (Rimi et al. 2016, 2017). Anthropologists piloted messages to increase awareness about avian influenza and its prevention in two rural communities, and explored change in villagers' awareness and behaviours attributable to the intervention. Even when farmers know about biosecurity they do not implement it. Villagers evoked Black Swan reasoning: they keep seeing a low risk of avian influenza. Investment in biosecurity is costly, impracticable, inconvenient and cause personal discomfort. They fear being rebuked or ridiculed by their neighbours, when they take precautions during times with no avian flu outbreak. In general, they tended to doubt the necessity of behaviour change (ibid.). We suggest that preventive action is particularly socially unacceptable during Black Swan periods of no disease outbreaks in poultry. Following poor farmers' reasoning, why would they pay for such luxury, when their birds are 'healthy'?

\section{Sacrifices and compromises}

We argue that poor farmers with little investment capital operate in a world of sacrifices and compromises. Looking to the past is cheaper than looking to the future. This may explain the temporalities of risk perception with regard to biosecurity among farmers, as preventive behaviour turns into reactive behaviour. Sacrifices and compromises among farmers include minimizing losses, selling sick birds, ignoring (costly) preventive behaviours, not investing in biosecurity and preferring indirect trade as a matter of convenience, though they know that direct trade would be more profitable. Rehanul, a credit farmer, recites a Bengali proverb: "Father's name will come if I survive". This relates to 'self-preservation as the foremost task', an expression of self-consciousness. Rehanul explains: "When I lose money, how can I think about others' profit or safety! I need to care for my own interests first. I need to minimize my losses".

The evidence from this research strongly suggests that farmers make rational choices through such compromises in order to survive, making a profit to feed the family. Biosecurity is a luxury they cannot afford. It would be irrational to invest in future-oriented preventive practices, when what matters is the immediate short-term perspective and, simultaneously, your risk perception is oriented towards the pastan example of Taleb's Black Swan hindsight bias (Taleb 2007). Already dire socioeconomic circumstances make the perceived risk of an avian influenza outbreak seem more improbable. Moreover, biosecurity makes little sense when you know little about what it necessitates in practice. Preventive practices are part of the preparedness paradigm and this fails to take into consideration the reality of farmers' everyday lives and the way things are including the temporalities of risk 
perception: orientation towards the past, practical experience, changing risk perception and practices during and in between disease outbreaks. We suggest, whatever farmers do, their behaviours are pragmatic and rational. It is what makes sense in order to survive and feed their families. By not investing in preventive practices to avoid the transmission of avian influenza viruses, a poor farmer is acting rationally-within the given context and circumstances of his or her life. Normative future-oriented preventive behaviour as defined in the global preparedness paradigm does not make sense to poultry farmers in Bangladesh give their circumstances and in particular in a political context of an unregulated poultry sector. This applies also to their rationalities in relation to risks to their own health.

It might seem contradictory that on one hand they state that they see no risk in their work, while on the other that they plan to invest in biosecurity. This apparent contradiction relates to the following factors. First, they refer to human health risks -and implicitly that there is no risk of zoonotic disease transmission. They say that personal protective equipment is too costly and uncomfortable. Second, risk perception decreases during times of no disease outbreaks. Third, most farmers have no clear idea about biosecurity, both what the term and its implied practices mean for humans and animals alike. Some farmers have 'a plan', which might include 'a boundary wall' and/or 'disinfection practices', but few farmers have an idea of comprehensive standards of farm biosecurity.

\section{Temporalities of risk perception}

Taking feed dealers, middlemen, poultry transporters and farmers together, they perceive the risk of avian influenza as low and are unlikely to be concerned about the potentially huge adverse impact. Such temporalities of risk perception phenomenon can be explained by social consent (Douglas and Wildavsky 1982), practical intelligibility (Schatzki 2002), convergence of constraints and motivation (Ortner 1984) and calculated risk (Taleb 2007).

First, tacit social consent in the poultry sector predicates a certain cultural bias towards selective risk management: "The choice of risks and the choice of how we live are taken together" (Douglas and Wildavsky 1982, p. 50). This view implies that social life and thus common values regulate the perception of risk to produce what is 'taken for granted' and thus 'normal'. We see a tendency that people involved in the poultry sector fear other business risks more than disease-associated business risks. The norm of the majority prevails. Farmers do what other farmers do. Feed dealers do what other feed dealers do. As Dider explained earlier: people using personal protective equipment would raise suspicion among customers, whether the birds are sick.

Second, how can they take action against avian influenza realizing that it cannot be dealt with in any practical way? As a practice theory, Theodore Schatzki invoked the idea of practical intelligibility as what makes sense to a person with regard to a course of action. This is not necessarily in accordance with reason, logic or normativity: "what makes sense for someone to do is not the same as or what is or 
what seems to be to the actor to be, appropriate, right or correct" (Schatzki 2002, p. 75).

Third, practical intelligibility is portrayed as an individualist phenomenon, and it would therefore at first not explain social consent among the actors. However, Schatzki argues that social phenomena influence individual practices. In anthropological terms, this is a convergence of constraints and (lack of) motivation (Ortner 1984).

For example, feed dealers and middlemen seem to subordinate animal and human disease concerns to other business risks. Rather, they may choose to live with disease risk, hoping that nothing happens, while recognizing that immediate and tangible business risks must be dealt with and knowing how to do this. This is practical intelligibility: what makes sense to individual actors under the given circumstances (Schatzki 2002). While this may not sound rational and logical, we argue that in such circumstances disease risk has become a calculated risk, a normalized part of everyday business, as implied in Black Swan theory (Taleb 2007). Avian influenza is seen as a rare and unpredictable event.

Yet, we do question whether the actors have an interest in protection against avian influenza and what would motivate them to do so, considering the limited resources and the reluctance among those who would be able to invest in risk management. Such motivation would need to depend on individual, social and political risk perception and recognition, which would lead to action. This recognizes a social representation approach to risk perception, emphasizing the complex content of common-sense thinking regarding particular risks, determined by consensus-making and social influences (Joffe 2003; Douglas 1992). Moreover, Ortner, building on Bourdieu's concepts of praxis and habitus and Sahlin's work on agency and structure, maintains that "a theory of practice is a theory of history": What people can do to change their actions is culturally and historically contingent (Ortner 1989, p. 193).

The different risk perceptions exemplify a case of uneven access to resources. Farmers, feed dealers and middlemen do not share profit and loss. In other words, they do not share risk. The farmers who engage in oral agreements with feed dealers -non-binding, yet morally, ethically and culturally binding contracts that rest upon trust and loyalty - are forced to repay the credit incurred under any circumstances, which minimizes their financial capital to invest in biosecurity. For all independent farmers, their profit margin is very small.

\section{An assemblage of risk perceptions and biosecurity practices}

The Black Swan hindsight perspective as described and analysed here from an anthropological perspective challenges its counterpart. At a time of rapidly intensifying production to provide affordable protein, the avian influenza pandemic preparedness paradigm emphasizes foresight preventive measures such as vaccination and investment in various forms of biosecurity, prioritizing and promoting improvements in veterinary infrastructure, surveillance systems, communication, awareness and research (Martinot et al. 2007; FAO 2011). Here, biosecurity refers to "the sum of the measures taken to prevent incursion and spread of disease" (Sims 
2008). Specifically, "Biosecurity includes the concept and measures of preventing introduction and spread of new infectious agents into flocks ('Bioexclusion'), and the potential and need to reduce the risk for flocks to spread disease to others ('Biocontainment')" (Thieme 2007, pp. 2-3). Such preparedness depends on government and poultry sector financial and human resources.

The theory of risk behind pandemic preparedness is a double-edged sword: the calculable and the incalculable. On one hand, its premise rests on a technicoscientific approach to risk, the assumption that risk can be monitored and measured scientifically. This is the taken for granted understanding of risk and does not problematize how scientific measurement of risk is constructed as a social fact (Lupton 2013, p. 28). Indeed, while such probabilistic accounts of risk can be used to anticipate disease outbreaks and resources for disease control (Hinchliffe et al. 2013, p. 536), the preparedness paradigm approaches events characterized by incalculable probability with a simplicity which opens the way to potentially catastrophic consequences should such events materialize (Lakoff 2007). In other words, the preparedness paradigm brings together the predictable and unpredictable, both focussed on the time ahead.

We have focussed on conceptual, structural and operational biosecurity in farms (Shane 2005). Conceptual biosecurity refers to factors related to the location of the farm, affecting the likelihood of viral incursions or release. Once the farm is established, the farmer has no control over these factors, which include distance from the main road, location of residential accommodation, poultry farms, backyard birds and water bodies and trees. Structural biosecurity (bioexclusion) measures prevent virus incursion, i.e. the entrance of infected birds, contaminated humans, wild or domestic animals, vehicles and equipment. Operational biosecurity (biocontainment) measures aim to prevent the release of viruses from infected poultry populations. It includes sanitation, disinfection, control of traffic (humans, vehicles, rodents and wild birds) and health monitoring and vaccination of birds (Chowdhury et al. 2015).

Our attention to lived experience and everyday practices adds an empirical human perspective on risk and biosecurity, as opposed to multispecies ethnographies of avian influenza that have focussed on 'narratives' (Lowe 2010) and 'risk mapping' (Porter 2012a). Social science studies recognize a plurality of 'biosecurity'. Biosecurity is about safety. It implies a sense of uncertainty, unpredictability, precariousness, probability, danger and risk. It has been defined in different contexts, such as farm-based practices; emerging infectious diseases; the life sciences; food safety; measures against bioterrorism and border control for the regulation of the spread of infectious agents (Collier and Lakoff 2008; Keck 2008), yet it is understood differently by different actors, for example, as between farmers, veterinarians, policy makers, governments, scientists and the general public (Enticott and Wilkinson 2013).

\section{Contact zones: a convergence of circumstances}

In this context, anthropology offers an emphasis on contact zones, constituted by social relations between humans, animals and viruses. Studying contact zones-an 
important aspect of intensification-emphasizes the nature-culture perspective on how subjects are constituted in and by their relations to each other (Kirksey and Helmreich 2010). Specifically, multispecies ethnographers focus on how living organisms (viruses, humans, animals) shape and are shaped by political, economic and cultural forces. This is a way to examine social relations between humans and non-humans and it makes good sense in the Bangladeshi poultry sector, where there is a diversity of contact zones between people, poultry and viruses-a context suitable for the improbable Black Swan event.

Contact zones may host certain hotspots, defined differently in epidemiological studies. A 'hot spot' originally meant "a location with high biodiversity and wildlife density that was under significant threat of degradation or destruction as a consequence of human activities" (Paige et al. 2015, p. 79). Later, a 'hot spot' meant a virus 'dissemination point' or a 'high risk area' (Ahmed et al. 2012a; Gilbert et al. 2010), or a geographical area prone to the emergence of zoonotic infectious diseases (Baudon et al. 2017). In anthropology, a hot spot refers to a convergence of circumstances that create the conditions for disease communicability, ethnographically focused on intimate interactions between humans, animals and viruses (Brown and Kelly 2014). Through innovative methodological pathways following birds and people through the poultry commodity chain, we show that individual and collective behavioural preferences and risk perceptions may, inadvertently, shape risky transactions that increase the risk of avian influenza virus transmission, between animals and from animals to humans. Such convergence of circumstances exemplifies a Black Swan-its improbable and unpredictable nature, yet with a massive impact, when it eventually occurs.

The underlying premise is to think of the movement of birds as a "commodity hood': commodity phase, candidacy and context (Appadurai 1986a; Kopytoff 1986). Appadurai provides a social analysis of things, extending the Marxian focus on commodities in the production processes. The social life of a thing concentrates on its total trajectory between production, exchange, distribution and consumption. It is defined as "the situation in which its exchangeability (past, present, future) for some other thing is its socially relevant feature" (Appadurai 1986a, p. 13). The ethnographic appeal resides in the biographic approach to things. The motionless bird in itself is uninteresting; the social relationships through birds are interesting. Methodologically, things-in-motion clarify their human and social context. The ethnographic revelation relevant to the birds' epidemiological status comes through following the thing, its meanings, uses and trajectories in the hands of people. This allows us to interpret and understand the human transactions that vitalize things and accord them cultural meanings (ibid., p. 5). Our analytical focus on commodity chains captures the focus on transactions in exchange, whereby value is removed at each point in the hierarchy. Such meanings are epidemiologically significant.

In epidemiology, poultry networks have indeed been shown to be heterogeneous and connected through a diversity of actors and animals (Rasamoelina-Andriamanivo et al. 2014). Heterogeneity in circumstances of overall intensification may influence the spread of viruses and have theoretical implications for a social science of avian influenza. Charles Perrow argued that systems with many non-linear interactions that are also tightly coupled are eventually bound to fail (Perrow 1999). 
In normal accident theory, he argues that risk is embedded in two key dimensions: coupling and complexity. These are both aspects of intensification and things flow rapidly through a tightly coupled system, in which all parts are connected. As in the case of the foot and mouth epidemic in the UK, poultry trade networks encompass a complex system in the plural sense through its multitude of connections, paths, flows, directions and mobilities (Law 2006; Hinchliffe et al. 2013). This constitutes a dynamics of risk in the sense that the flow of a virus exemplifies a patterned web of partially connected flows in which the multiple intersection flows produces potential leaks (Law 2006, p. 10). Such flows are similarly seen in many other systems, for example, in trade, human mobility and in safety and hygiene systems.

Birds flow rapidly through a poultry network. In fact, birds must flow rapidly as consumable commodities with both economic and sanitary underpinnings. As opposed to a linear system, where the flow tends to be one-directional, live birds in Bangladesh flow through a complex heterogeneous system, unidirectionally between production sites, market maker scenes and outlets.

\section{The Black Swan}

Black Swan theory provides explanatory power for such convergence of circumstances with the temporalities of risk perception phenomenon at its core. The actors measure risk retrospectively, combined with an assessment of the resources available at hand in the present, not prospectively. This is a hindsight bias. This may influence the way the actors calculate risk, which stands in contrast to how risk is calculated in the foresight preparedness paradigm. The key actors in the Chittagong poultry commercial trading network from independent farmers discussed here are aware of the risk of economic loss in case of severe disease outbreaks, but they may circumvent such scenario by entering the birds into the commodity chain early, e.g. at a lower price or quickly. These are ways of lowering adverse effects on their livelihood, even if the probability of infection may be high. This may indicate that they have developed strategies to mitigate economic losses, resulting in disease in their view no longer being a major business risk, although these mitigation strategies may increase the risk of infection-for birds and humans alike-along the commodity chain. However, such scenario encompasses a contradiction: for those farmers who have not yet experienced avian influenza, the chance of an outbreak remains a contemplated risk (Kousky et al. 2010). An outbreak has not occurred, but they recognize past occurrences. Yet, due to their low to non-existent knowledge about avian influenza, they are not able to discuss this disease in scientific terms-or even just in terms that mean something to them. What goes on in Bangladesh among the actors in terms of risk perception and management is a case of 'Black Swan dynamics'. 


\section{Implications for risk management}

Our analysis has focused on temporalities of risk perception with regard to biosecurity among hatchery managers, feed dealers, middlemen, poultry transporters and farmers. Policy advancement requires an awareness and recognition of the complex nature of biosecurity. It requires a widened biopolitical inspection that recognizes the fractured nature of biosecurity along the commodity chain. In fact, it has been pointed out that the complexity of avian influenza disease and biosecurity commonly is not identified in official publications (Hinchliffe and Bingham 2008, p. 1542). Are the complex stories of bird flu transmission being neglected, in favour of simple linear stories of origin and effect? Lowe suggests that "the conventional avian influenza 'outbreak narrative' leaves important sources of contagion out of the picture" (Lowe 2010, p. 641). In other words, the linear story of bird flu transmission from wild birds to domestic and farm birds to humans implies a particular intervention strategy (Rabinow and Rose 2006, p. 197). We suggest that well-intentioned concern with public health inadvertently favours certain kinds of poultry production methods, while perhaps neglecting the fact that the poultry sector in Bangladesh will remain a multi-tiered system of parallel and unequal means to manage and control infectious diseases, that is, co-existing biosecurity standards (hatcheries, industrial farms, independent live bird farms, strict versus moderate, low or no control, common slaughterhouses versus live bird markets). Independent farmers explain that their profit remains unpredictable, which makes biosecurity unaffordable. Biosecurity will therefore be compromised. The rule of common practice and imitation prevails among peers. This raises questions in the plural sense: we are witnessing a scale of technologies among competing actors in the poultry sectors and biosocial contexts (Kleinman et al. 2008).

Avian influenza remains an economic and social disease: sick or dead birds impact production and people's lives. It embraces social life, context and process, in which biosecurity and risk management depends on human organization. Indeed, anthropologists have shown the difficulties in defining and managing avian flu risk: the uncertainty among scientists and regulators in the US, the UK and Vietnam (Porter 2016), in managing bio-risks in France, Germany and the UK (Lentzos and Rose 2009), competing descriptions of animals and their habitats in zoonotic disease contexts in Vietnam (Porter 2012a) and the uncertainty about the nature and consequences of avian influenza in Indonesia (Lowe 2010). By focussing on risk and biosecurity along the live bird commodity chain between independent production sites, market maker scenes and outlets, we emphasize the divergent and competing risk rationalities drawing attention to the unpredictable nature of avian influenza. Such ethnographic findings may not have been captured in epidemiological studies. We have shown that the poultry commodity chain between farms and markets may host risky spaces-contact zones and hotspots that may serve as routes of pathogenic transmission and contagion. However, we emphasize that the anthropological meaning of a disease hotspot includes the lack or absence of resources to control diseases in the context of abundant pathogens (Brown and Kelly 2014, p. 293; Sodikoff 2017, p. 118). 
The dynamics of such disease ecology raises compelling questions about improving risk management in the Bangladeshi poultry sector. Which approach is the more cost-effective: pragmatically taking things as they come, applying reactive measures, counting the loss and recovering? It is cheaper to calculate risk retrospectively, as implied in our interpretation of Black Swan theory. In other words, should participants in the trading system continue living with risk, considering the limited resources in Bangladesh and the perceived low probability of a disease outbreak? Or should steps be taken to invest in preventive risk management that safeguard against dangers in the unknown future as implied in the preparedness paradigm?

Considering the 'insecurity' and the lack of knowledge about avian flu and how to engage with it among the actors in the poultry commodity chain, we suggest reframing the meaning of 'biosecurity'. It could develop into an inclusive alternative socio-ecology of disease and health, not just about hygiene and health benefits, but also welfare, vulnerability, cost, convenience and comfort. Yet, such socioecological definition of biosecurity would decisively depend on a changing political ecology of animal and human health and disease by the Bangladeshi government, continuously constrained by lack of human resources and inadequate health facilities and equipment, recognized by the government many years ago.

The allegorical comparison of a rare event is a bird itself: the question remains how best to engage with the Black Swan, particularly considering the widespread perception that H5N1 outbreaks will not happen again. This is also a Black Swan. Here we show the contradictions between actor worldviews in the everyday poultry business as contrasted with standard epidemiological thinking and commonly proposed interventions. We question whether the actors are underestimating the likelihood and consequences of avian influenza virus contamination of birds and humans, in farms and along the poultry commodity chain. People in the poultry sector have their own perception of disease risk and how to manage it in their daily coping with immediate business risks. In epidemiological terms, their attitudes and responses may be incongruent with the current situation of disease risk, but this should not suggest that their responses arise from 'ignorance'. In anthropological terms, we should recognize that their responses are rooted in their focus on a time span and knowledge which is not inaccurate but merely incongruent with the epidemiological picture. Unpicking and responding to this incongruity should inform our understanding of how to formulate policy interventions.

Acknowledgements We are thankful to the study participants for their time and information. In response to a security situation in Bangladesh, affecting foreign field researchers, fieldwork was carried out in collaboration with 8 research assistants from Chittagong Veterinary and Animal Sciences University (CVASU) between September 2015 and January 2016. These participating investigators, who have experience with epidemiological avian influenza research, received training by the main author on how to conduct ethnographic fieldwork. We thank in particular BALZAC Research Assistant Rashed Mahmud, who organized initial communication with informants and led substantial proportions of the data production in collaboration with the late Fakhrul Islam (1990-2017), Rubyath Hasan, Brishti Barua, Shohel Rana, Kazi Rukon, Billal Uddin and Nur Mohammad. We thank the Bengali-English translators Professor Abdul Ahad and Assistant Professor Abdul Rahman. In particular, for the research at live bird 
markets, we thank the interpreter anthropologist Ahmed Suja Uddin, Chittagong University. We would also like to thank the anonymous reviewers of this paper for their comments and suggestions.

Funding This study received funding from the BALZAC research programme Behavioural Adaptations in Live Poultry Trading and Farming Systems and Zoonoses Control in Bangladesh. This is one of 11 programs funded under Zoonoses \& Emerging Livestock Systems, ZELS, a joint research initiative between Biotechnology and Biological Sciences Research Council (BBSRC) (Grant No. BB/L018993/1), Defense Science and Technology Laboratory (DSTL), Department for International Development (DFID), Economic and Social Research Council (ESRC), Medical Research Council (MRC) and Natural Environment Research Council (NERC). The funders had no involvement in the conduct of the research or preparation of this paper.

\section{Compliance with ethical standards}

Conflict of interest The authors declare that they have no competing interests.

Ethical approval The Institutional Review Board, Institute of Epidemiology, Disease Control and Research, IEDCR, Dhaka and the Observational Research Ethics Committee, London School of Hygiene \& Tropical Medicine, ethically approved this ethnographic study. We provided an informed consent statement translated into Bengali, which explained the aims, objectives and affiliations of this study. It promised voluntary participation and confidentiality. It was read aloud for the illiterate. The names used are pseudonyms to protect the anonymity of informants.

Open Access This article is distributed under the terms of the Creative Commons Attribution 4.0 International License (http://creativecommons.org/licenses/by/4.0/), which permits unrestricted use, distribution, and reproduction in any medium, provided you give appropriate credit to the original author(s) and the source, provide a link to the Creative Commons license, and indicate if changes were made.

\section{References}

Ahmed, S.S.U., A.K. Ersbøll, P.K. Biswas, et al. 2012a. Ecological Determinants of Highly Pathogenic Avian Influenza (H5N1) Outbreaks in Bangladesh. PLoS ONE 7 (3): e33938.

Ahmed, S.S.U., G.E. Themudo, J.P. Christensen, et al. 2012b. Molecular Epidemiology of Circulating Highly Pathogenic Avian Influenza (H5N1) Virus in Chickens, in Bangladesh, 2007-2010. Vaccine 30 (51): 7381-7390.

Appadurai, A. 1986a. Introduction: Commodities and the Politics of Value. In The Social Life of Things: Commodities in Cultural Perspective, ed. A. Appadurai, 3-63. Cambridge: Cambridge University Press.

Appadurai, A. (ed.). 1986b. The Social Life of Things. Commodities in Cultural Perspective. Cambridge: Cambridge University Press.

Baudon, E., G. Fournié, D.T. Hiep, et al. 2017. Analysis of Swine Movements in a Province in Northern Vietnam and Application in the Design of Surveillance Strategies for Infectious Diseases. Transboundary and Emerging Diseases 64 (2): 411-424.

Begum, I.A., S. Rahman, M.J. Alam, et al. 2011. Bangladesh Poultry Sector: Growth, Competitiveness and Future Potential. In Livestock: Rearing, Farming Practices and Diseases Animal Science, Issues and Professions, ed. M.T. Javed, 81-104. New York: Nova Science Publishers Inc.

Bouma, A., I. Claassen, K. Natih, et al. 2009. Estimation of Transmission Parameters of H5N1 Avian Influenza Virus in Chickens. PLoS Pathogens 5 (1): e1000281.

Brooks, W.A., A.S. Alamgir, R. Sultana, et al. 2009. Avian Influenza Virus A (H5N1), Detected Through Routine Surveillance, in Child, Bangladesh. Emerging Infectious Diseases 15 (8): 1311-1313.

Brown, H., and A.H. Kelly. 2014. Material Proximities and Hotspots: Toward an Anthropology of Viral Hemorrhagic Fevers. Medical Anthropology Quarterly 28 (2): 280-303.

Chowdhury, E.H., Das, P.M., Islam, M.R. et al. 2015. Quantification of Biosecurity Status in Commercial Poultry Farms Using A Scoring System. In 9th International Poultry Show and Seminar, Dhaka: World's Poultry Science Association, Bangladesh Branch, 173-184. https://en.engormix.com/ 
poultry-industry/articles/quantification-biosecurity-status-commercial-t41111.htm. Accessed 14 Aug 2018.

Collier, S.J., and A. Lakoff. 2008. The Problem of Securing Health. In Biosecurity Interventions: Global Health \& Security in Question, ed. A. Lakoff and S.J. Collier, 7-32. New York: Columbia University Press.

Douglas, M. 1992. Risk and Blame: Essays in Cultural Theory. London: Routledge.

Douglas, M., and A. Wildavsky. 1982. How Can We Know the Risks We Face? Why Risk Selection is a Social Process. Risk Analysis 2 (2): 49-58.

Enticott, G., and A. Wilkinson. 2013. Biosecurity: Whose Knowledge Counts? In Biosecurity: The SocioPolitics of Invasive Species and Infectious Diseases, ed. A. Dobson, K. Barker, and S.L. Taylor, 91104. London: Routledge.

Falzon, M.-A. 2009. Introduction. Multi-sited Ethnography: Theory, Praxis and Locality in Contemporary Research. In Multi-sited Ethnography: Theory, Praxis and Locality in Contemporary Research, ed. M.-A. Falzon, 1-23. Aldershot: Ashgate.

FAO. 2011. Approaches to Controlling, Preventing and Eliminating H5N1 Highly Pathogenic Avian Influenza in Endemic Countries. Rome: Food and Agriculture Organization. http://www.fao.org/ docrep/014/i2150e/i2150e.pdf. Accessed 14 Aug 2018.

FAOSTAT. 2015. Live Animal Production in Bangladesh: Chickens and Ducks. http://faostat3.fao.org/ download/Q/QA/E. Accessed 29 Apr 2018.

Gilbert, M., S.H. Newman, J.Y. Takekawa, et al. 2010. Flying over an Infected Landscape: Distribution of Highly Pathogenic Avian Influenza H5N1 Risk in South Asia and Satellite Tracking of Wild Waterfowl. EcoHealth 7 (4): 448-458.

Gregory, N.G., P.K. Biswas, and S.H. Chowdhury. 2010. Recent Concerns About the Environment in Bangladesh. Outlook on Agriculture 39 (2): 115-120.

Hammersley, M., and P. Atkinson. 2007. Ethnography: Principles in Practice, 3rd ed. London: Routledge.

Haraway, D.J. 2008. When Species Meet. Posthumanities. Minneapolis: University of Minnesota Press.

Hinchliffe, S., J. Allen, S. Lavau, et al. 2013. Biosecurity and the Topologies of Infected Life: From Borderlines to Borderlands. Transactions of the Institute of British Geographers 38 (4): 531-543.

Hinchliffe, S., and N. Bingham. 2008. Securing Life: The Emerging Practices of Biosecurity. Environment and Planning A 40 (7): 1534-1551.

Hulse-Post, D.J., K.M. Sturm-Ramirez, J. Humberd, et al. 2005. Role of Domestic Ducks in the Propagation and Biological Evolution of Highly Pathogenic H5N1 Influenza Viruses in Asia. Proceedings of the National academy of Sciences of the United States of America 102 (30): 1068210687.

ICDDRB. 2011. Outbreak of Mild Respiratory Disease Caused by H5N1 and H9N2 Infections Among Young Children in Dhaka, Bangladesh, 2011. Health and Science Bulletin 9 (2): 5-12.

ICDDRB. 2013. The First Fatal Human Infection with Highly Pathogenic Avian Influenza A (H5N1) Virus Detected in Bangladesh. Health and Science Bulletin 11 (3): 1-6.

IEDCR. 2012a. Fifth and Sixth H5N1 Human Case in Bangladesh. 5 March. Dhaka: Institute of Epidemiology, Disease Control and Research. http://www.iedcr.gov.bd/pdf/files/influenza/Fifth_ and_Sixth_H5N1.pdf. Accessed 14 Aug 2018.

IEDCR. 2012b. Fourth H5N1 Human Case in Bangladesh. 27 February. Dhaka: Institute of Epidemiology, Disease Control and Research. http://iedcr.gov.bd/pdf/files/influenza/Fourth-H5N1human-case-in-Bangladesh.pdf. Accessed 14 Aug 2018.

Joffe, H. 2003. Risk: From Perception to Social Representation. British Journal of Social Psychology 42 (1): 55-73.

Keck, F. 2008. From Mad Cow Disease to Bird Flu. Transformations of Food Safety in France. In Biosecurity Interventions: Global Health \& Security in Question, ed. A. Lakoff and S.J. Collier, 195225. New York: Columbia University Press.

Kirksey, S.E., and S. Helmreich. 2010. The Emergence of Multispecies Ethnography. Cultural Anthropology 25 (4): 545-576.

Kirksey, S.E., C. Schuetze, and S. Helmreich. 2014. Tactics of Multispecies Ethnography. In The Multispecies Salon, ed. S.E. Kirksey, 1-24. Durham: Duke University Press.

Kleinman, A.M., B.R. Bloom, A. Saich, et al. 2008. Asian Flus in Ethnographic and Political Context: A Biosocial Approach. Anthropology \& Medicine 15 (1): 1-5. 
Kopytoff, I. 1986. The Cultural Biography of Things: Commoditization as Process. In The Social Life of Things: Commodities in Cultural Perspective, ed. A. Appadurai, 64-91. Cambridge: Cambridge University Press.

Kousky, C., J. Pratt, and R. Zeckhauser. 2010. Virgin Versus Experienced Risks. In The Irrational Economist: Making Decisions in A Dangerous World, ed. E. Michel-Kerjan and P. Slovic, 99-106. New York: Public Affairs.

Lakoff, A. 2007. Preparing for the Next Emergency. Public Culture 19 (2): 247-271.

Law, J. 2006. Disaster in Agriculture: Or Foot and Mouth Mobilities. Environment and Planning A 38 (2): 227-239.

Lentzos, F., and N. Rose. 2009. Governing Insecurity: Contingency Planning, Protection, Resilience. Economy and Society 38 (2): 230-254.

Lowe, C. 2010. Viral Clouds: Becoming H5N1 in Indonesia. Cultural Anthropology 25 (4): 625-649.

Lupton, D. 2013. Risk. Key Ideas, 2nd ed. London: Routledge.

Marcus, G.E. 1995. Ethnography in/of the World System: The Emergence of Multi-sited Ethnography. Annual Review of Anthropology 24 (1): 95-117.

Marcus, G.E. 2002. Beyond Malinowski and After "Writing Culture": On the Future of Cultural Anthropology and the Predicament of Ethnography. The Australian Journal of Anthropology 13 (2): 191-199.

Marcus, G.E. 2007. Ethnography Two Decades After Writing Culture: From the Experimental to the Baroque. Anthropological Quarterly 80 (4): 1127-1145.

Martinot, A., J. Thomas, A. Thiermann, et al. 2007. Prevention and Control of Avian Influenza: The Need for a Paradigm Shift in Pandemic Influenza Preparedness. Veterinary Record 160 (10): 343-345.

MoFL. 2006. National Avian Influenza and Human Pandemic Influenza Preparedness and Response Plan Bangladesh 2006-2008. Dhaka: Ministry of Fisheries and Livestock, Government of the People's Republic of Bangladesh. http://www.un-influenza.org/sites/default/files/files/National_Avian_ Influenza_And_Human_Pandemic_Influenza_Preparedness_and_Response_Plan_2006-2008_1.pdf. Accessed 29 Apr 2018.

MoFL. 2009. 2nd National Avian and Pandemic Influenza Preparedness and Response Plan, Bangladesh 2009-2011. Dhaka: Ministry of Fisheries and Livestock, Government of the People's Republic of Bangladesh. http://dghs.gov.bd/bn/licts_file/images/Plan/2009_2nd_Pandemic_Influenza_ Preparedness_Plan.pdf. Accessed 14 Aug 2018.

MoP. 2015. 7th Five Year Plan FY2016-FY2020. Accelerating Growth, Empowering Citizens. Dhaka: Ministry of Planning, Government of the People's Republic of Bangladesh. http://www.plancomm. gov.bd/7th-five-year-plan-2/. Accessed 14 Aug 2018.

Nasreen, S., and S.U. Khan, E. Azziz-Baumgartner. 2013. Seroprevalence of Antibodies against Highly Pathogenic Avian Influenza A (H5N1) Virus among Poultry Workers in Bangladesh, 2009. PLoS One, 8 (9): e73200.

Ogden, L.A., B. Hall, and K. Tanita. 2013. Animals, Plants, People, and Things: A Review of Multispecies Ethnography. Environment and Society: Advances in Research 4 (1): 5-24.

OIE. 2013. Bangladesh: Follow-up Report No. 43 (Final Report). 21/12/2013. Paris: World Organisation for Animal Health. http://www.oie.int/wahis_2/public\%5C..\%5Ctemp\%5Creports/en_fup_ 0000014568_20131223_145541.pdf. Accessed 14 Aug 2018.

OIE. 2018. Bangladesh: Update on Avian Influenza in Animals (Types H5 and H7). Paris: World Organization for Animal Health. http://www.oie.int/en/animal-health-in-the-world/update-on-avianinfluenza/2018/. Accessed 14 Aug 2018.

Ortner, S.B. 1984. Theory in Anthropology Since the Sixties. Comparative Studies in Society and History 26 (1): 126-166.

Ortner, S.B. 1989. High Religion: A Cultural and Political History of Sherpa Buddhism. Princeton Studies in Culture/Power/History. Princeton: Princeton University Press.

Osmani, M.G., M.P. Ward, M. Giasuddin, et al. 2014. The Spread of Highly Pathogenic Avian Influenza (Subtype H5N1) Clades in Bangladesh, 2010 and 2011. Preventive Veterinary Medicine 114 (1): 2127.

Paige, S.B., C. Malavé, E. Mbabazi, et al. 2015. Uncovering Zoonoses Awareness in an Emerging Disease 'Hotspot'. Social Science and Medicine 129: 78-86.

Perrow, C. 1999. Normal Accidents: Living with High-Risk Technologies. Princeton, NJ: Princeton University Press.

Porter, N. 2012a. Risky Zoographies: The Limits of Place in Avian Flu Management. Environmental Humanities 1: 103-121. 
Porter, N. 2012b. Threatening Lives: Controlling Avian Flu in Vietnam's Poultry Economy. PhD thesis, The University of Wisconsin, Madison, Ann Arbor.

Porter, N. 2013. Bird Flu Biopower: Strategies for Multispecies Coexistence in Việt Nam. American Ethnologist 40 (1): 132-148.

Porter, N. 2016. Ferreting Things Out: Biosecurity, Pandemic Flu and the Transformation of Experimental Systems. BioSocieties 11 (1): 22-45.

Rabinow, P., and N. Rose. 2006. Biopower Today. BioSocieties 1 (2): 195-217.

Rasamoelina-Andriamanivo, H., R. Duboz, R. Lancelot, et al. 2014. Description and Analysis of the Poultry Trading Network in the Lake Alaotra Region, Madagascar: Implications for the Surveillance and Control of Newcastle Disease. Acta Tropica 135: 10-18.

Rimi, N.A., R. Sultana, K. Ishtiak-Ahmed, et al. 2016. Understanding the Failure of a Behavior Change Intervention to Reduce Risk Behaviors for Avian Influenza Transmission Among Backyard Poultry Raisers in Rural Bangladesh: A Focused Ethnography. BMC Public Health 16 (1): 1-15.

Rimi, N.A., R. Sultana, M. Muhsina, et al. 2017. Biosecurity Conditions in Small Commercial Chicken Farms, Bangladesh 2011-2012. EcoHealth 1-15.

Schatzki, T.R. 2002. The Site of the Social: A Philosophical Account of the Constitution of Social Life and Change. University Park: Pennsylvania State University Press.

Shane, S.M. 2005. Handbook on Poultry Diseases, 210. St. Louis: American Soybean Association.

Sims, L.D. 2008. Risks Associated with Poultry Production Systems. In Poultry in the 21st Century: Avian Influenza and Beyond, ed. O. Thieme and D. Pilling, 355-378. Rome: FAO.

Sodikoff, G.M. 2017. Multispecies Epidemiology and the Viral Subject. In The Routledge Companion to the Environmental Humanities, ed. U.K. Heise, J. Christensen, and M. Niemann, 112-119. London: Routledge.

Spradley, J. 1980. Participant Observation. London: Harcourt Brace Jovanovich College Publishers.

Taleb, N.N. 2004. Learning to Expect the Unexpected. Edge: The Third Culture, https://www.edge.org/ 3rd_culture/taleb04/taleb_indexx.html. Accessed 18 Dec 2017.

Taleb, N.N. 2007. The Black Swan. The Impact of the Highly Improbable, 401. New York: Random House.

Thieme, O. 2007. Trends, Issues and Options in Applying Long Term Biosecurity Measures on Production Systems and Sector Structure. Technical Meeting on Highly Pathogenic Avian Influenza and Human H5N1 Infection, 27-29 June 2007, Rome: FAO, 9, http://www.fao.org/docs/eims/ upload//229373/ah658e.pdf. Accessed 14 Aug 2018.

WHO. 2008. Avian Influenza-Situation in Bangladesh. Geneva: World Health Organization. http://www. who.int/csr/don/2008_05_28/en/. Accessed 14 Aug 2018.

WHO. 2011a. Avian Influenza-Situation in Bangladesh. Geneva: World Health Organization. http:// www.who.int/csr/don/2011_03_16/en/. Accessed 14 Aug 2018.

WHO. 2011b. Avian Influenza-Situation in Bangladesh-Update. Geneva: World Health Organization. http://www.who.int/csr/don/2011_04_11a/en/. Accessed 14 Aug 2018.

WHO. 2013. Influenza at the Human-Animal Interface. Summary and Assessment as of 26 April 2013. Geneva: World Health Organization. http://www.who.int/influenza/human_animal_interface/ Influenza_Summary_IRA_HA_interface_26Apr13.pdf. Accessed 14 Aug 2018.

WHO. 2015. Influenza at the Human-Animal Interface. Summary and Assessment as of 4 September 2015. Geneva: World Health Organization. http://www.who.int/influenza/human_animal_interface/ Influenza_Summary_IRA_HA_interface_04_September_2015.pdf?ua=1. Accessed 14 Aug 2018.

WHO. 2016 Influenza at the Human-Animal Interface. Summary and Assessment as of 20 January 2016. Geneva: World Health Organization. http://www.who.int/influenza/human_animal_interface/ Influenza_Summary_IRA_HA_interface_20_Jan_2016.pdf?ua=1. Accessed 14 Aug 2018.

World Bank. 2015. World Development Indicators: Bangladesh. Washington DC: World Bank. http:// data.worldbank.org/country/bangladesh. Accessed 18 Dec 2017.

Erling Høg, anthropologist, is a Research Fellow in Social Science, Department of Global Health and Development, London School of Hygiene \& Tropical Medicine. He leads the anthropological BALZAC project in Bangladesh: An initial ethnographic investigation of practices and rationales among people working with poultry in live bird markets and other parts of the transaction chain. 
Guillaume Fournié is a Research Fellow in Veterinary Epidemiology, Department of Pathobiology and Population Sciences, Royal Veterinary College.

Md. Ahasanul Hoque is a Professor of Veterinary Epidemiology and National Coordinator of the ZELS Project, Faculty of Veterinary Medicine, Chittagong Veterinary and Animal Sciences University.

Rashed Mahmud is a veterinarian and ZELS Research Assistant, Faculty of Veterinary Medicine, Chittagong Veterinary and Animal Sciences University.

Dirk Pfeiffer is a Chair Professor of One Health, City University of Hong Kong \& Royal Veterinary College.

Tony Barnett is a Professorial Research Fellow in the Social Sciences of Infectious Diseases, Department of Global Health and Development, London School of Hygiene \& Tropical Medicine and Honorary Professor, Humanitarian and Conflict Response Institute, University of Manchester. Jointly, this team of researchers combines methodological expertise in veterinary epidemiology and modelling, public health and social science in the study of avian influenza in Bangladesh. 